Article

\title{
Preparation of a Fast Water-Based UV Cured Polyurethane-Acrylate Wood Coating and the Effect of Coating Amount on the Surface Properties of Oak (Quercus alba L.)
}

\author{
Jin Wang ${ }^{1,2}$, Huagui $\mathrm{Wu}^{3}$, Ru Liu ${ }^{3} \oplus$, Ling Long ${ }^{1,3, *}$, Jianfeng $\mathrm{Xu}{ }^{1,3}$, Minggui Chen ${ }^{4}$ and \\ Hongyun Qiu ${ }^{3}$ \\ 1 Research Institute of Forestry New Technology, Chinese Academy of Forestry, Haidian, Beijing 100091, China \\ 2 Kingdecor (Zhejiang) Co., Ltd., Quzhou 324000, China \\ 3 Research Institute of Wood Industry, Chinese Academy of Forestry, Haidian, Beijing 100091, China \\ 4 Jiangsu Himonia Technology Co., Ltd., Jurong 212400, China \\ * Correspondence: longling@caf.ac.cn; Tel.: +86-10-62889425
}

Received: 31 July 2019; Accepted: 27 August 2019; Published: 28 August 2019

\begin{abstract}
A fast water-based ultraviolet light (UV) curing polyurethane-acrylate (PUA) wood coating was prepared in the laboratory, and applied on oak (Quercus alba L.) at different coating amounts. The PUA wood coating can be fast cured within $22 \mathrm{~min}$, which highly improved the drying speed compared to normal water-based wood coatings (often higher than $35 \mathrm{~min}$ ). The coating amounts affected the coating properties after curing on oak. With the increase of coating amount, the adhesion, hardness and gloss value of surface increased to different extents. Meanwhile, the surface of sample became smooth gradually because the voids of the oak were filled. Thus, higher coating amount resulted in better coating properties. However, no significant increase of penetration depth was found. During curing, the hydroxyl groups of the wood reacted with the coating. The optimal parameter in this study was the coating amount of $120 \mathrm{~g} / \mathrm{m}^{2}$, where the adhesion reached 1 (with $0-5 \%$ cross-cut area of flaking along the edges), with the hardness of $2 \mathrm{H}$ and the gloss of $92.56^{\circ}$, which met the requirement of Chinese standard GB/T 18103-2013, and could be used for engineered wood flooring.
\end{abstract}

Keywords: water-based UV curing coating; coating amount; surface properties; polyurethane-acrylate; oak (Quercus alba L.)

\section{Introduction}

In recent years, with the improvement of environmental protection regulations and people's awareness, water-based wood coatings have become a research hotspot [1-5]. Water-based polyurethane acrylate (PUA) coatings are widely used owing to their wear-resistance, stain resistance, and ease of use [6]. They can form a variety of hydrogen bonds between molecular chains due to their functional acrylic groups and urethane bonds, which provides the coatings with weather resistance, solvent resistance, comprehensive mechanical properties and excellent appearance on wood products [7-10]. At the same time, the molecular structure and functionality can be adjusted to satisfy the different needs of furniture, cabinets, office and laboratory equipment. In addition, during film formation, little or no volatile organic compounds (VOCs) evaporate into the atmosphere, therefore they can be considered low cost and pollution-free.

However, a problem that has restricted the application of water-based coatings is their relatively slow drying rate compared with solvent-based coatings. It is known that the latent heat of water is much higher than that of organic solvents, such as benzene, xylene, etc. Besides, some properties 
of water-based coatings are not comparable to those of solvent-based coatings, like low hardness, and gloss. To expand the application of coatings to other areas, ultraviolet light (UV) curing technology is used in the manufacture of water-based coatings for fast curing [11-13]. UV cured coatings use high energy UV lights as sources, which can form coating films via self-polymerization [14]. Most UV-curable resins consist of multifunctional acrylate monomers and oligomers associated to an aromatic ketone that generates upon UV-exposure free radicals which will initiate the crosslinking polymerization [15]. Therefore, the PUA could meet these requirements. Some kinds of water-based UV curing PUA coatings have been investigated $[15,16]$. However, up to present, the water-based UV curing coatings have not really been applied on wooden products due to the limitations of the coating film properties.

It is well known that the properties of coatings are affected by many factors, such as the environment, degree of wetting between the coating and the substrate, chemical or physical effects, surface properties of the substrate, and so on [17-22]. Yang et al. [23] found that different environments could cause differences in the chemical composition on the surface of the PUA painting film and the surface morphology was thus different. Masson et al. [16] also found that basic coating performance features such as the drying speed were highly dependent on the temperature and film thickness.

Accordingly, many researchers have investigated the basic properties of the resin particles and the impact of paint in different environments [24-29]. However, the influence of the coating amount on the resulting surface performance of the coating has been less investigated, let alone for fast water-based UV curing PUA wood coatings. Coating amount, as a very important factor, affects the performance of cured coatings very much. At low coating amount, the coating thickness is thin and insufficient coverage will be obtained, while with an excessive amount of coating, drying defects such as wrinkles, and bubbling may occur. Therefore, in this paper, a kind of fast water-based UV curing coating was synthesized in the laboratory, and applied on oak for its wide application in furniture, flooring and other industries due to its resource advantages and good decorative properties in the solid wood market [30-32]. The effect of coating amount on the surface properties such as the surface morphology, chemical changes, permeability and surface energy was studied, with the aim to provide some basic data and reference for the application of the fast water-based UV curing wood coatings.

\section{Materials and Methods}

\subsection{Materials}

Oak (Quercus alba L.) wood which originated from Fujian Province in the southeast of China was purchased from a Beijing home building materials market. The wood was dried to a $8-10 \%$ moisture content prior to use. The oak was then sawn into slabs with dimensions of $630 \mathrm{~mm}(\mathrm{~L}) \times 120 \mathrm{~mm}(\mathrm{~T}) \times$ $20 \mathrm{~mm}(\mathrm{R})$. The slabs were sanded with 240 mesh sandpaper and the dust was removed to ensure that the substrate surface was clean. The reagents for the fast water-based UV curing PUA wood coating are listed in Table 1. All abbreviations concerning the reagents used are presented in parentheses in Table 1.

\subsection{Synthesis of the Fast Water-Based UV Curing PUA Coating}

The fast water-based UV curing PUA coating was prepared based on our previous study [33]. According to Table 1, the first step was to prepare a pre-polyacrylate emulsion. Monomers (24 g of $\mathrm{AA}, 4 \mathrm{~g}$ of ST, and $7 \mathrm{~g}$ of EA) were blended with $169 \mathrm{~g}$ of distilled water in a three-neck glass flask at $150 \mathrm{r} / \mathrm{min}$. Afterwards, the initiator ( $8 \mathrm{~g}$ of APS) was added at $10 \mathrm{wt} \%$. For the next $70-90 \mathrm{~min}$, the rest of the monomers ( $96 \mathrm{~g}$ of AA, $16 \mathrm{~g}$ of ST, and $133 \mathrm{~g}$ of EA) was added dropwise into the reactor. Afterwards, the rest of the initiator (32 $\mathrm{g}$ of APS) and $36 \mathrm{~g}$ of KH550 were added dropwise into the reactor within 90-110 min. The reactor was heated up to $85^{\circ} \mathrm{C}$ and held at this temperature for $4 \mathrm{~h}$. The next step was to graft the pre-polyurethane onto the pre-polyacrylate chain. TDI (100 g), PEG-400 (200 g) and DBTD (8g) were dissolved in N-methyl-2-pyrrolidone solvent and blended into a three-neck glass flask at $150 \mathrm{r} / \mathrm{min}$. The reactor was heated to $40^{\circ} \mathrm{C}$. While stirring, HEA (66 g) was dripped into 
the reactor within $2 \mathrm{~h}$. The pre-polyurethane was thus obtained. Afterwards, both the pre-polyacrylate and pre-polyurethane were mixed in the three-neck glass flask and blended at $150 \mathrm{r} / \mathrm{min}$. The reaction mixture was heated up to $85{ }^{\circ} \mathrm{C}$ and kept at that temperature for $2 \mathrm{~h}$. The pre-PUA emulsion was obtained after cooling and filtration. Defoamer agent $(0.2 \%)$, photoinitiator $(2 \%)$, and HDDA diluting agent $(1.5 \%)$ were added into the emulsion at $100 \mathrm{r} / \mathrm{min}$ for $10 \mathrm{~min}$. Then, the water-based UV curing PUA coating was obtained. After good dispersion, the coating was prepared and stored in a black bottle against light.

Table 1. Reagents for water-based UV curing PUA coating.

\begin{tabular}{ccc}
\hline Reagent & Function & Manufacturer \\
\hline Ammonium persulfate (APS) & Initiator & 1 \\
Acrylic acid (AA) & Monomer & 1 \\
Styrene (ST) & Monomer & 1 \\
Ethyl acrylate (EA) & Monomer & 1 \\
Hydroxyethyl acrylate (HEA) & Monomer & 1 \\
Toluene-2,4-diisocyanate (TDI) & Monomer & 1 \\
Polyethylene glycol (Mn: 400) (PEG-400) & Monomer & 1 \\
Dibutyltin dilaurate (DBTD) & Catalyst & 1 \\
N-methyl-2-pyrrolidone & Solvent & 1 \\
Hexanediol diacrylate (HDDA) & Diluting agent & 1 \\
r-Aminopropyl triethoxysilane (KH550) & Silane & 2 \\
Polyether siloxane copolymer composition & Defoamer agent & 3 \\
2-Hydroxymethylphenylpropan-1-one & Photoinitiator & 4
\end{tabular}

Notes: (1) Xilong Chemical Co.Ltd (Guangzhou.China); (2) Qufu Chengguang Chemical Co., Ltd (Shandong, China); (3) TEGO AIREX 901W; (4) Germany Evonik tego.

\subsection{Coating on a Wood Sample}

The coating amount was determined as a variable, and an uncoated wood slab was used as a control. The wet coating coating amount weights were 12,60 , and $120 \mathrm{~g} / \mathrm{m}^{2}$, respectively. The coating process was carried out by on an auto-coating rolling machine bracket with pressure. The coating speed was $80 \mathrm{~mm} / \mathrm{s}$. The drying temperature of the hot air dryer used in this test was determined to be $35^{\circ} \mathrm{C}$. The dryer mesh was subjected to a drying cycle of 2 min with 10 drying cycles, where the removal of water was achieved. Then, the coating it was cured by a UV curing machine. The photocuring energy was $250-350 \mathrm{~mJ} / \mathrm{cm}^{2}$ for $2 \mathrm{~min}$.

\subsection{Characterizations and Tests}

The solid content of PUA was measured according to Chinese Standard GB/T 1725-2007 by drying the PUA coating at $125^{\circ} \mathrm{C}$ for $1 \mathrm{~h}$ based on the residual percent of the coating. The viscosity was determined by a viscometer (NDJ-5S, Shanghai Pingxuan Scientific Instrument Co., Ltd., Shanghai, China). The average particle size of PUA was measured by a laser scattering particle distribution analyzer (MPT-Z, Malvern, London, UK).

The macro-structure was observed by an optical stereomicroscope (Leica S9 series, Jena, Germany). The microstructures of the above samples were observed by scanning electron microscope (SEM, JEOL JSM-6301F, Tokyo, Japan) with an acceleration voltage of $20 \mathrm{kV}$. The samples were sputter-coated with gold.

The dried coating thickness was measured by an ultrasonic velocity gauge (AT-140S, Guangzhou Amittari Design, Co. Ltd., Guangzhou, China). The throughout-dry state of the coating after $22 \mathrm{~min}$ of curing was tested following the ISO 9117:1990 standard with a plunger machine. The adhesion classification of coating films with wood was measured according to the ISO 2409:2013 standard method by a cross-cut test. The gloss values of the coatings were determined by the ISO 2813:2014 method using a geometry of $60^{\circ}$. Coating hardness was determined by ISO standard 15184:2012 by a pencil test. 
Specimens including coated and uncoated oak were investigated. The chemical groups of the samples were examined by Fourier transform infrared spectroscopy (FTIR, BRUKER Vertex 70v, Hamburg, Germany) equipped with an attenuated total reflection (ATR) accessory. The surfaces were put in contact with the $\mathrm{ZnSe}$ crystal at a $45^{\circ}$ angle of incidence.

The contact angle of pure oak with testing liquid (distilled water) and solution of $70 \mathrm{wt} \%$ PUA coating was measured according to ISO 15989:2004 by a contact angle meter (ISO, 2004; Krüss K11MK4, Hamburg, Germany). The contact angles of coated wood with different coating amounts with distilled water was also measured.

The surface morphologies were captured by atomic force microscopy (AFM) and collected by a scanning probe microscope in contact mode. The scanning area was $2 \mu \mathrm{m} \times 2 \mu \mathrm{m}$. The surface roughness was tested by a surface roughness tester using a stylographic method (SF200 Basic, Beijing Shidaishanfeng Technology Co. Ltd., Beijing, China). The values of the average profile error ( $\mathrm{Ra})$, maximum height $(\mathrm{Rp})$, maximum valley depth $(\mathrm{Rv})$, maximum profile height $(\mathrm{Rt})$ and Maximum peak-valley height $(\mathrm{Rz})$ were obtained.

Energy dispersed X-ray analysis (EDXA, Horiba 7021-H, Tokyo, Japan) was carried out in SEM analysis mapping mode. The PUA coated samples were cut vertically. The image and distribution of elemental N, mainly from the PUA resin, was captured digitally to allow further analysis of the penetration of PUA into each substrate.

\section{Results and Discussion}

\subsection{Morphologies}

Figure 1 shows images of the fast water-based UV curing PUA coating and the coated wood samples. It can be seen that the synthesized PUA coating was a stable and transparent liquid. Table 2 lists some parameters of the fast water-based UV curing PUA coating, such as the solid content, viscosity, and average particle size. It can be found that the PUA coating had very high solid content of $90 \mathrm{wt} \%$, while the viscosity was not very high. The particle size of the PUA coating ranged from $80 \mathrm{~nm}$ to $500 \mathrm{~nm}$ (Figure 2) with an average value of $226 \mathrm{~nm}$. Images of PUA coated oak are seen in Figure $1 \mathrm{~b}-\mathrm{d}$. From the images, all wood samples were well coated by the PUA coating with a layer of coating film.

Table 2. Parameters of fast water-based UV curing PUA coating.

\begin{tabular}{cc}
\hline Parameter & Values \\
\hline Solid content & $90 \mathrm{wt} \%$ \\
Viscosity & $50 \mathrm{mpa} \cdot \mathrm{s}$ \\
Average particle size & $226 \mathrm{~nm}$ \\
\hline
\end{tabular}

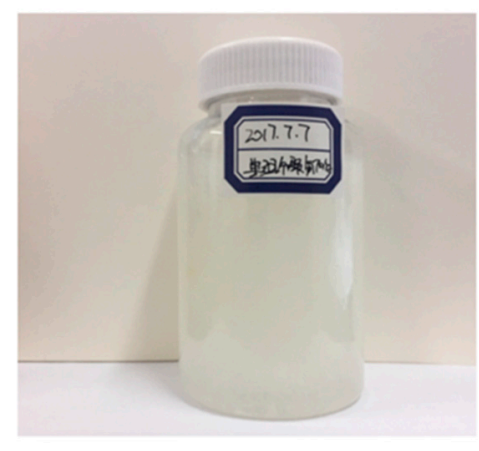

(a)

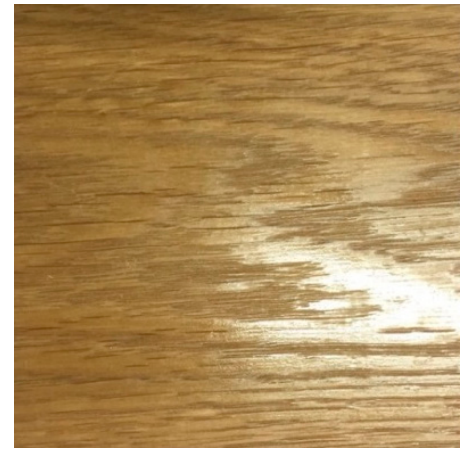

(b)

Figure 1. Cont. 


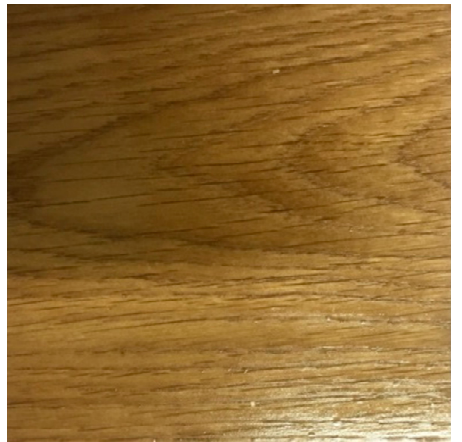

(c)

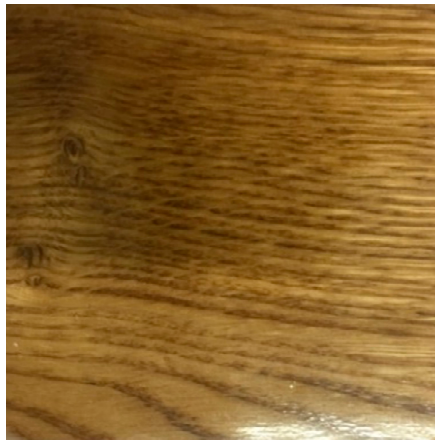

(d)

Figure 1. Images of PUA coating and its coated oak samples at different coating amounts. (a) PUA coating; (b) $12 \mathrm{~g} / \mathrm{m}^{2}$ PUA coated oak; (c) $60 \mathrm{~g} / \mathrm{m}^{2}$ PUA coated oak; (d) $120 \mathrm{~g} / \mathrm{m}^{2}$ PUA coated oak.

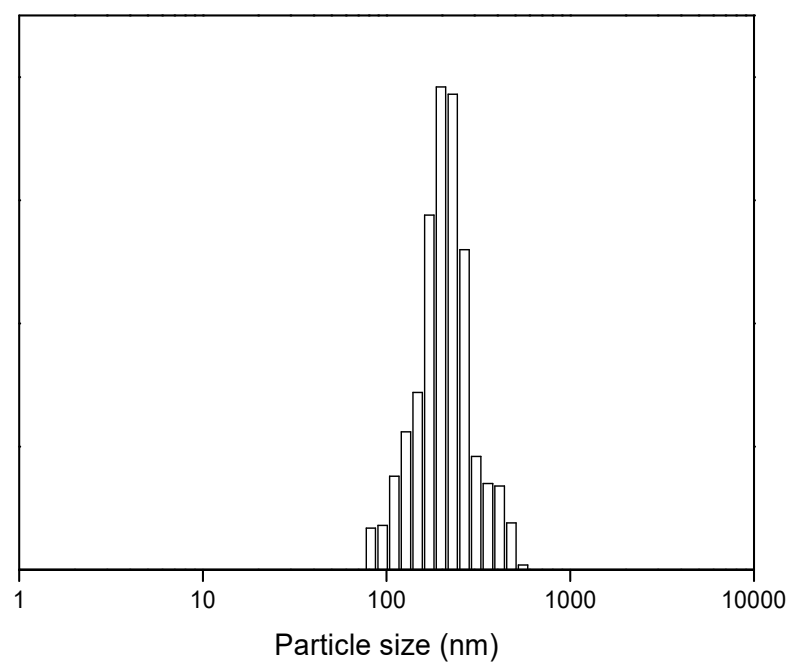

Figure 2. Particle size distribution of the PUA coating.

Figure 3 shows a visual microscope picture of the oak surface with different coating amounts under an optical stereomicroscope. The wood samples were covered by the coating films. Besides, it can be seen that as the coating amount increased, the surface of the paint film became smoother. When the coating amount was $12 \mathrm{~g} / \mathrm{m}^{2}$, the oak vessels were partly occupied by paint, but most regions were still exposed. When the coating amount increased to $60 \mathrm{~g} / \mathrm{m}^{2}$, the vessels were substantially filled with few defects.

The surface morphologies of oak under different coating amounts tested by SEM are shown in Figure 4. The microstructures of the oak were clearly visible before painting. After the surface was coated with PUA coating, the microstructures were covered to varying degrees at different coating amounts. Within a certain range, as the coating amount increased, the surface smoothness of the sample gradually increased, which was consistent with the roughness values (discussed in the following part). In the case of $12 \mathrm{~g} / \mathrm{m}^{2}$ coated samples, the coating surface was incompletely covered, and some oak microstructures were exposed, namely, the surface of the painted film had a large number of grain protrusions, and the surface was rough. As the coating amount increased, the surface coverage of the oak increased, where the oak vessels could not be seen. 


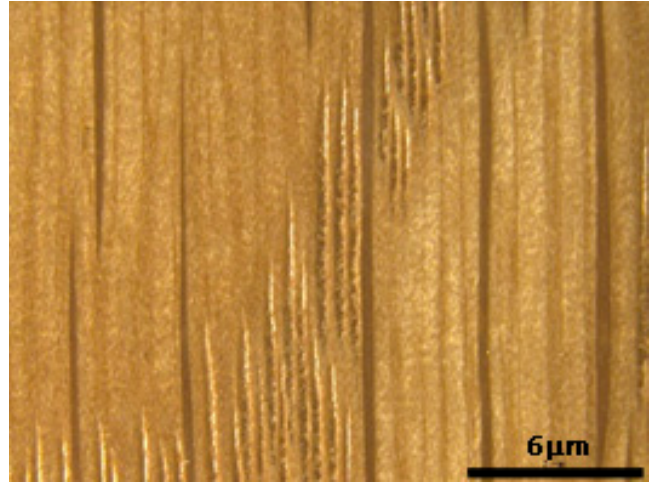

(a)

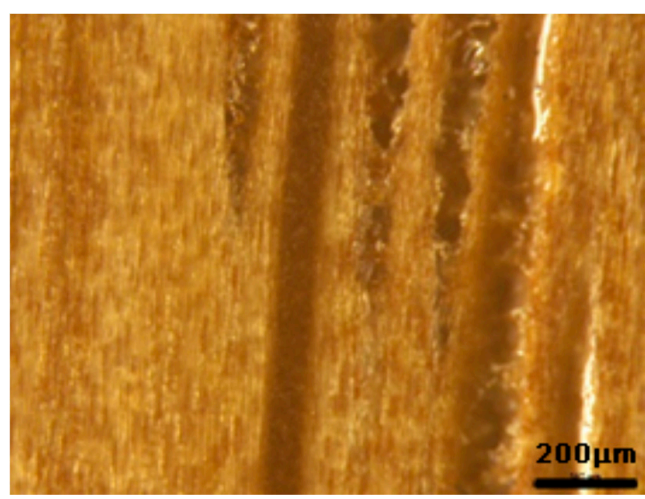

(c)

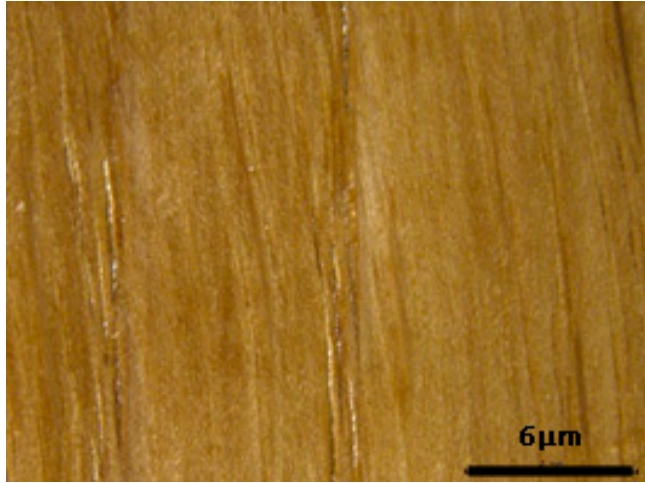

(b)

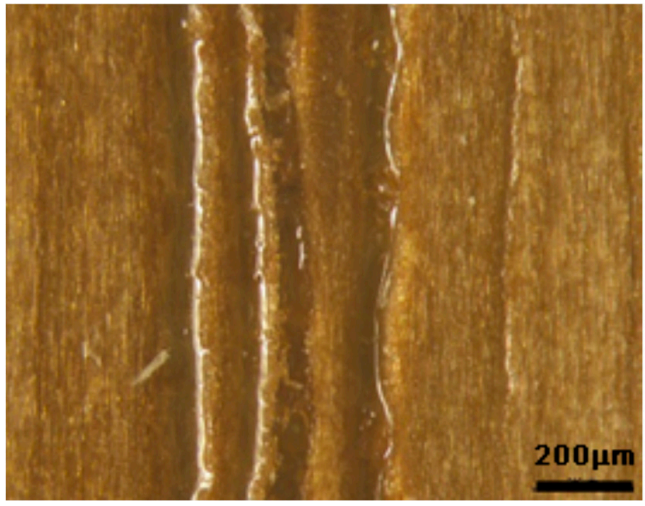

(d)

Figure 3. Optical microscope images of oak after coating at different coating amounts. $(\mathbf{a}, \mathrm{c}) 12 \mathrm{~g} / \mathrm{m}^{2}$ PUA coated oak; (b,d) $60 \mathrm{~g} / \mathrm{m}^{2}$ PUA coated oak.

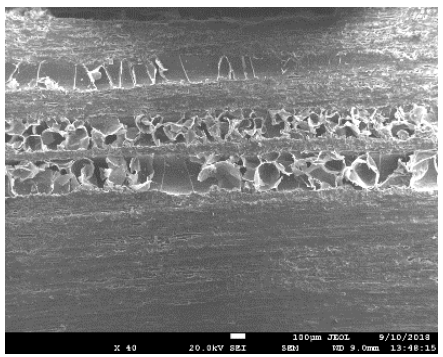

(a)

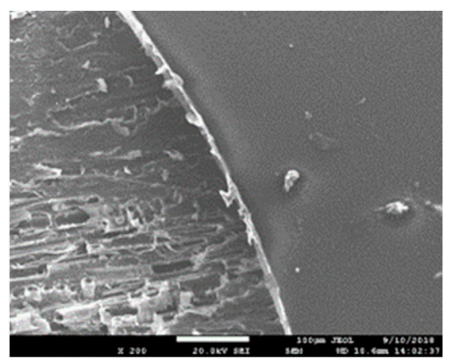

(d)

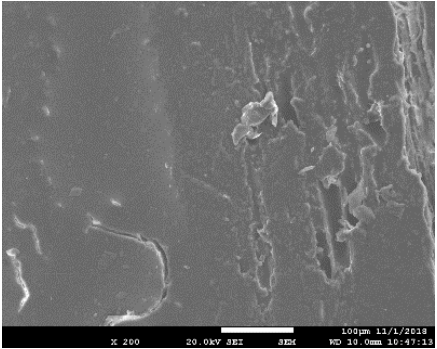

(b)

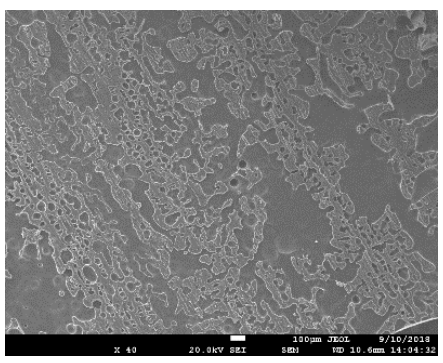

(e)

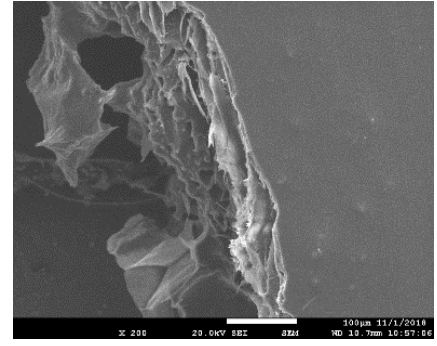

(c)

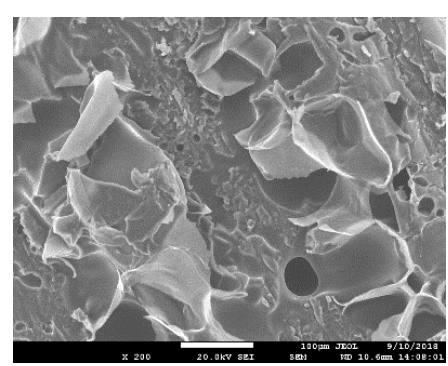

(f)

Figure 4. SEM images of oak before and after coating at different coating amount. (a) pure oak; (b) $12 \mathrm{~g} / \mathrm{m}^{2}$ PUA coated oak; (c) $60 \mathrm{~g} / \mathrm{m}^{2}$ PUA coated oak; (d) $120 \mathrm{~g} / \mathrm{m}^{2}$ PUA coated oak; (e,f) the back surface of coating peeling from the oak; $(\mathbf{a}, \mathbf{e})$ the magnification was $\times 40 ;(\mathbf{b}-\mathbf{d}, \mathbf{f})$ the magnification was $\times 200$. 
In order to further understand the adhesion between PUA coating and wood, the painted film was peeled off from the test piece, and the morphology of the back was observed (Figure 4e,f). It can be seen from the figure that the back of the paint film exhibited a microscopic topography similar to that of oak. However, some tyloses were easily found, which may be caused by the adhesion of coating in the vessels during drying of the water.

From the morphology results, it can be concluded that the PUA coating can form a layer of film that covers on the surface of the oak after 22 min of curing. Besides, we tested the drying state of all coatings according to ISO 9117:1990, and found no damage or markings on the surfaces. Therefore, the coatings were completely dried and be cured on oak by this process, which is much faster than the Chinese standard requirement for water-based coatings of 30-60 min (Table 3).

Table 3. Technical requirements for coatings and the related wooden products.

\begin{tabular}{ccccc}
\hline Technical requirements & Standards & $\begin{array}{c}\text { Adhesion } \\
\text { classification }\end{array}$ & $\begin{array}{c}\text { Pencil } \\
\text { hardness }\end{array}$ & $\begin{array}{c}\text { Curing } \\
\text { time (min) }\end{array}$ \\
\hline $\begin{array}{c}\text { Water-based coatings for woodenware for } \\
\text { indoor decorating and refurbishing }\end{array}$ & GB/T 23999-2009 & $\leq 1$ & $\geq \mathrm{B}$ & $30-60$ \\
\cline { 2 - 5 } UV curing coatings for woodenware & EN 927:2006 & $\leq 1$ & - & - \\
\hline HG/T 3655-2012 & $\leq 2$ & $\geq \mathrm{H}$ & - \\
\hline Wooden furniture & GB/T 3324-2017 & $\leq 3$ & - & - \\
Solid wood floor & GEN/TS 16209:2011 & $\leq 2$ & - & - \\
\hline Engineered wood floor & GB/T 15036-2018 & $\leq 3$ & $\geq \mathrm{H}$ & - \\
\hline Indoor wood-based door & ISO 17959:2014 & $\leq 3$ & $\geq \mathrm{H}$ & - \\
Wood-based wall-board & EN 14354-2005 & $\leq 2$ & $\geq 2 \mathrm{H}$ & - \\
\hline & LY/T 1923-2010 & $\leq 2$ & $\geq \mathrm{HB}$ & - \\
\hline
\end{tabular}

Besides, the PUA coating has good adhesion to wood, because the back surface was similar to the morphology of wood. Therefore, the preparation and application of the fast water-based UV curing PUA wood coating was successful.

\subsection{Basic Properties of PUA Coated Oak}

The basic properties including dried coating thickness, adhesion, hardness, and gloss of the PUA coated oak samples are listed in Table 4. As the coating amount increased, the dried thickness, adhesion, hardness, and gloss of the sample were improved. By comparing with dried coating thickness values, it seemed that the dried coating thickness did not increase linearly. For example, at a coating amount of $120 \mathrm{~g} / \mathrm{m}^{2}$, the dried coating thickness was $74 \mu \mathrm{m}$, which was 21 times the dried coating thickness at $12 \mathrm{~g} / \mathrm{m}^{2}$. It may be that the surface of the sample was not completely covered at the coating amount of $12 \mathrm{~g} / \mathrm{m}^{2}$, and more PUA molecules were penetrated into the wood substrate, resulting in a low adhesion, hardness and surface gloss of the paint film. When the coating amount increased to $60 \mathrm{~g} / \mathrm{m}^{2}$, the coverage was improved, therefore, the adhesion classification, hardness, and surface gloss of the sample were improved. When the coating amount was $120 \mathrm{~g} / \mathrm{m}^{2}$, the sample was completely covered with the paint film, where the adhesion classification reached level 1 with the hardness of $2 \mathrm{H}$ and the gloss of $92.56^{\circ}$.

By comparing with the technical requirements for some related wooden products given by Chinese and international standards, listed in Table 3, it can be inferred that at $60 \mathrm{~g} / \mathrm{m}^{2}$, the adhesion classification and pencil hardness of the PUA coating met the requirements for water-based coatings and UV curing coatings. Besides, the curing time is much less than the requirement of water-based coatings of 30-60 min. For wooden products, all PUA coated samples can be used for wooden furniture and wood-based wallboard. However, for indoor wood-based doors and solid wood floors, the coating 
amount should increase to $60 \mathrm{~g} / \mathrm{m}^{2}$, while for applying on engineered wood floors, the coating amount must be further increased to $120 \mathrm{~g} / \mathrm{m}^{2}$.

Table 4. Adhesion, hardness, and gloss of oak coated at different coating amounts.

\begin{tabular}{ccccc}
\hline Sample & $\begin{array}{c}\text { Dried coating } \\
\text { thickness }(\mu \mathrm{m})\end{array}$ & $\begin{array}{c}\text { Adhesion } \\
\text { classification }\end{array}$ & $\begin{array}{c}\text { Pencil } \\
\text { hardness }\end{array}$ & Gloss $\left(^{\circ}\right)$ \\
\hline $12 \mathrm{~g} / \mathrm{m}^{2}$ PUA coated oak & 3 & 2 & $\mathrm{~B}$ & 28.7 \\
$60 \mathrm{~g} / \mathrm{m}^{2}$ PUA coated oak & 34 & 1 & $\mathrm{H}$ & 83.2 \\
$120 \mathrm{~g} / \mathrm{m}^{2}$ PUA coated oak & 74 & 1 & $2 \mathrm{H}$ & 93.6 \\
\hline
\end{tabular}

\subsection{Chemical Analysis}

Figure 5a shows the ATR-FTIR results for oak and pure PUA coating. The characteristic absorption bands attributed to the polyurethane-acrylate coating are reflected in the figure based on the literature $[11,14,16]$. The peaks observed at $1554 \mathrm{~cm}^{-1}$ and $818 \mathrm{~cm}^{-1}$ were assigned to $-\mathrm{NH}$ in and out of plane bending vibrations, which indicated that $\mathrm{N}$ element was in the coating. Therefore, the penetration depth of the coating can be determined according to the $\mathrm{N}$ element. In addition, bands at $1184 \mathrm{~cm}^{-1}$, $1079 \mathrm{~cm}^{-1}$, and $907 \mathrm{~cm}^{-1}$ were attributed to the $\mathrm{C}-\mathrm{O}$ stretching vibrations, $\mathrm{C}-\mathrm{O}$ stretching vibrations in ether bonds, and acid -OH out-of-plane bending vibrations, respectively. These indicated that carboxylic acid functions may be present in the coating, which can be reacted with the hydroxyl groups in the wood. Meanwhile, bands at $1726 \mathrm{~cm}^{-1}$ and $1672 \mathrm{~cm}^{-1}$ are characteristic peaks of carbonyl $\mathrm{C}=\mathrm{O}$ and $\mathrm{C}=\mathrm{O}$ stretching vibrations in unsaturated acids. Besides, other characteristic peaks of PUA can be observed, such as the $1251 \mathrm{~cm}^{-1} \mathrm{C}-\mathrm{O}$ stretching vibration in ester bonds, $1016 \mathrm{~cm}^{-1} \mathrm{C}-\mathrm{OH}$ stretching vibrations, $1385 \mathrm{~cm}^{-1}-\mathrm{OH}$ in-plane bending vibrations, and $3390 \mathrm{~cm}^{-1}-\mathrm{OH}$ stretching vibration.
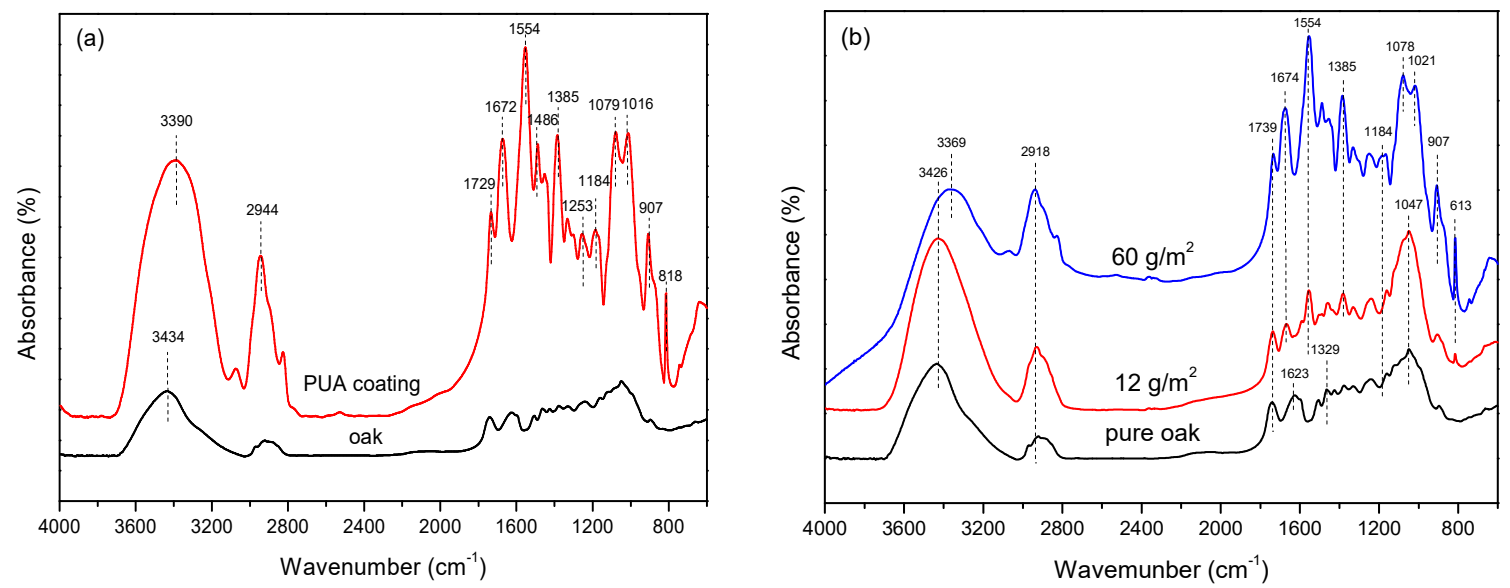

Figure 5. ATR-FTIR spectrum of samples. (a) Pure oak and PUA coating; (b) oak before and after coating with different coating amounts.

Figure $5 \mathrm{~b}$ shows the FTIR results of pure oak and oak coated with PUA at amounts of $12 \mathrm{~g} / \mathrm{m}^{2}$ and $60 \mathrm{~g} / \mathrm{m}^{2}$, respectively. The comparison shows that the PUA characteristic peak gradually becomes obvious with the increase of the coating amount. However, some characteristic peaks shifted compared with the PUA spectrum shown in Figure 5a. Compared with the oak, $12 \mathrm{~g} / \mathrm{m}^{2}$ and $60 \mathrm{~g} / \mathrm{m}^{2}$ coated samples owned many characteristic peaks, such as the characteristic absorption peak of $\mathrm{C}=\mathrm{O}$ stretching vibrations in unsaturated acids at $1674 \mathrm{~cm}^{-1}$, the absorption peak of $-\mathrm{NH}_{2}$ stretching vibrations at $1554 \mathrm{~cm}^{-1}$, and the $1184 \mathrm{~cm}^{-1} \mathrm{C}-\mathrm{O}$ stretching vibration. These vibration absorption peaks indicated that the PUA coating covered the surface of the oak and exhibited the characteristic PUA absorption peaks. As the coating amount increased, in the FITR of oak coated with $60 \mathrm{~g} / \mathrm{m}^{2}$ PUA one can clearly observe that some chemical groups changed compared with that coated with $12 \mathrm{~g} / \mathrm{m}^{2} \mathrm{PUA}$, indicating 
that some chemical reactions took place. In details, the absorption peaks at $1047 \mathrm{~cm}^{-1}$ disappeared, while $\mathrm{C}-\mathrm{O}$ stretching vibrations in ether bonds and $\mathrm{C}-\mathrm{OH}$ stretching vibrations appeared at $1078 \mathrm{~cm}^{-1}$ and $1021 \mathrm{~cm}^{-1}$. Additionally, the characteristic $-\mathrm{OH}$ out-of-plane bending vibration peaks at $907 \mathrm{~cm}^{-1}$, $-\mathrm{CH}_{2} / \mathrm{CH}_{3}$ stretching vibration peaks at $2918 \mathrm{~cm}^{-1},-\mathrm{OH}$ internal bending vibration at $1385 \mathrm{~cm}^{-1},-\mathrm{CH}_{2}$ out-of-plane bending vibrations at $613 \mathrm{~cm}^{-1}$, and out-of-plane bending vibrations at $818 \mathrm{c} \mathrm{m}^{-1}$ were obviously enhanced, showing the characteristics of PUA coating. Compared with pure PUA, the -OH absorption peak shifted to $3369 \mathrm{~cm}^{-1}$, and the $1021 \mathrm{~cm}^{-1} \mathrm{C}-\mathrm{OH}$ stretching vibration absorption peak was weakened, while the stretching vibration at $1184 \mathrm{~cm}^{-1}$ for $\mathrm{C}-\mathrm{O}$ was enhanced. This proved that the hydroxyl groups in the wood reacted with the coating by hydrogen bonds or by forming esters [34].

\subsection{Contact Angle}

Molecular interactions between the wood surface and the coating are also important in achieving good adhesion [35]. Figure 6 shows the image of contact angle of PUA droplets (70\% solids) and water on the oak surface. The results are listed in Table 5. The coating is not easily spread on the oak compared to water because the polarity of PUA is lower than that of water. Although the wettability of PUA is not as good as that of water, the contact angle of PUA droplets on oak was lower than $90^{\circ}$, indicating the PUA can evenly spread on the oak surface. The contact angle between PUA coated oak and water were also tested. The results showed that with the increase of coating amount, the contact angle of water droplets on the surface increased because of the covering of a layer of coating film. Compared with oak coated at $12 \mathrm{~g} / \mathrm{m}^{2}$ PUA amount, the $60 \mathrm{~g} / \mathrm{m}^{2}$ possessed a larger contact angle with water, which could be explained by the incompletely covered surface at $12 \mathrm{~g} / \mathrm{m}^{2}$ PUA amount, where the water might penetrate into the wood sample.

(a)

a)

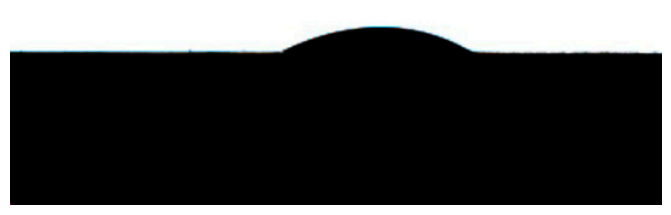

(c)

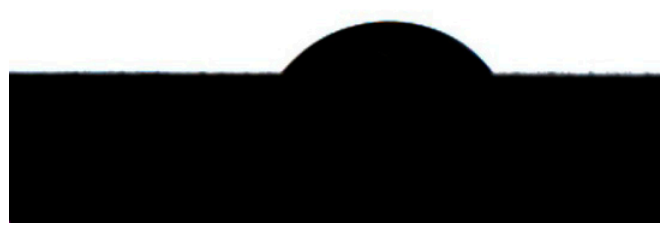

(b)

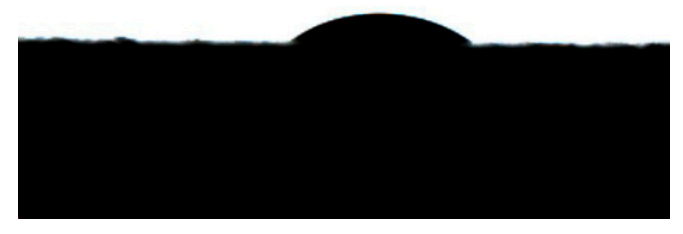

(d)

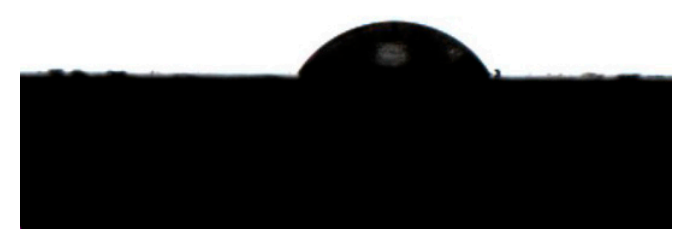

Figure 6. Contact angles of oak sample. (a) Pure oak with water; (b) pure oak with $70 \mathrm{wt} \%$ PUA droplet; (c) $12 \mathrm{~g} / \mathrm{m}^{2}$ PUA coated oak with water; (d) $60 \mathrm{~g} / \mathrm{m}^{2}$ PUA coated oak with water. 
Table 5. Contact angles of PUA droplets (70\% solids) and water on the oak surface.

\begin{tabular}{ccc}
\hline Sample & Testing liquid & Contact angle $\mathbf{(}^{\circ}$ ) \\
\hline Pure oak & Water & 29.68 \\
Pure oak & $70 \mathrm{wt} \%$ PUA droplet & 34.98 \\
$12 \mathrm{~g} / \mathrm{m}^{2}$ PUA coated oak & Water & 52.22 \\
$60 \mathrm{~g} / \mathrm{m}^{2}$ PUA coated oak & Water & 56.13 \\
\hline
\end{tabular}

\subsection{Surface Roughness}

Table 6 shows the surface roughness of oak coated with different coating amounts. As the coating amount increased, Ra decreased continuously, and all the surface roughness values showed the same tendency. The $\mathrm{Rp}$ and the Rv decreased with the increase of the coating amount, indicating that the vessels and surface irregularities of the oak were continuously filled by PUA coating. Thus, the roughness values decreased, and the surface became smooth.

Table 6. Roughness of oak before and after coating at different coating amount.

\begin{tabular}{cccccc}
\hline Sample & $\mathbf{R a}(\mu \mathbf{m})$ & $\mathbf{R p}(\mu \mathbf{m})$ & $\mathbf{R v}(\boldsymbol{\mu m})$ & $\mathbf{R t}(\boldsymbol{\mu m})$ & $\mathbf{R z}(\mu \mathbf{m})$ \\
\hline Pure oak & 3.456 & 5.930 & 12.521 & 55.110 & 18.450 \\
$12 \mathrm{~g} / \mathrm{m}^{2}$ PUA coated oak & 3.026 & 3.451 & 10.000 & 45.975 & 13.451 \\
$60 \mathrm{~g} / \mathrm{m}^{2}$ PUA coated oak & 2.422 & 1.651 & 6.924 & 48.010 & 8.577 \\
$120 \mathrm{~g} / \mathrm{m}^{2}$ PUA coated oak & 0.310 & 0.516 & 0.400 & 2.834 & 0.916 \\
\hline
\end{tabular}

The surface morphologies of the oak after coating at different amounts tested by AFM are shown in Figure 7. It can be seen from the figure that as the coating amount increased, the surface coverage of the oak increased, and the PUA coating can cover well on the oak under different coating amounts without obvious defects. Among them, when the coating amount was $12 \mathrm{~g} / \mathrm{m}^{2}$, the surface roughness value was $0.97 \mathrm{~nm}$. As for the surface with a coating amount of $60 \mathrm{~g} / \mathrm{m}^{2}$, many small protrusions were observed, and the surface paint film was rough after drying, and the surface roughness value was $4.08 \mathrm{~nm}$. Different from Table 5, it can be seen that the roughness of the coating increased with increasing coating amount, which might because that the paint surface was uneven, resulting in an increase in the surface roughness in a very small range.

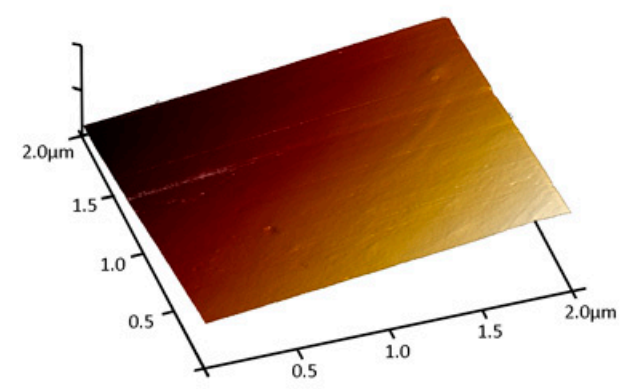

$\mathrm{Ra}: 0.968 \mathrm{~nm}, \mathrm{Rq}: 1.35 \mathrm{~nm}$

(a)

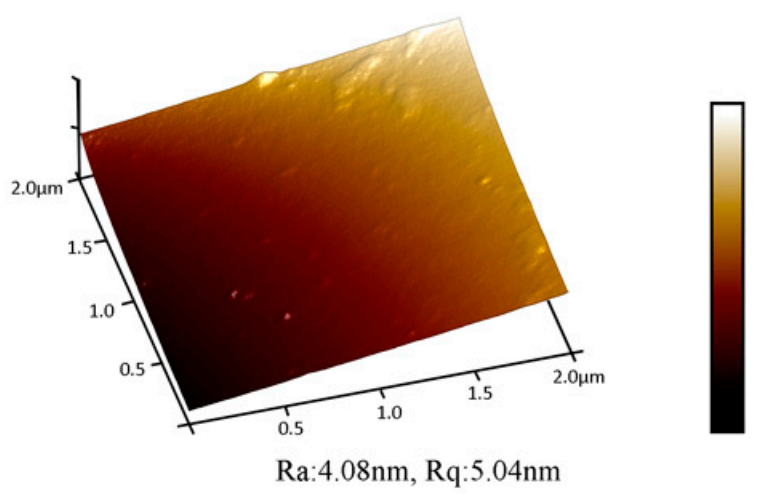

(b)

Figure 7. AFM images of oak after coating at different coating amount. (a) $12 \mathrm{~g} / \mathrm{m}^{2}$ PUA coated oak; (b) $60 \mathrm{~g} / \mathrm{m}^{2}$ PUA coated oak.

\subsection{Penetration of PUA in Wood}

In order to further analyze the permeability of different coatings in oak, the SEM-EDXA was performed on N-element (see red dots) for the coated samples. The results are shown in Figure 8. 
As seen from the figure, the PUA was distributed in a large amount on the surface of the substrate, and a small amount was penetrated into the substrate. At the coating amount of $12 \mathrm{~g} / \mathrm{m}^{2}$, the PUA penetration depth on the oak surface was about $20 \mu \mathrm{m}$, and the small portion reached $35 \mu \mathrm{m}$. When the coating amount increase to $60 \mathrm{~g} / \mathrm{m}^{2}$, the voids in the oak penetration depth of $35 \mu \mathrm{m}$ are substantially filled because of higher amount of PUA was applied. However, the penetration of the PUA coating in oak did not increase significantly, and $35 \mu \mathrm{m}$ was the limit.

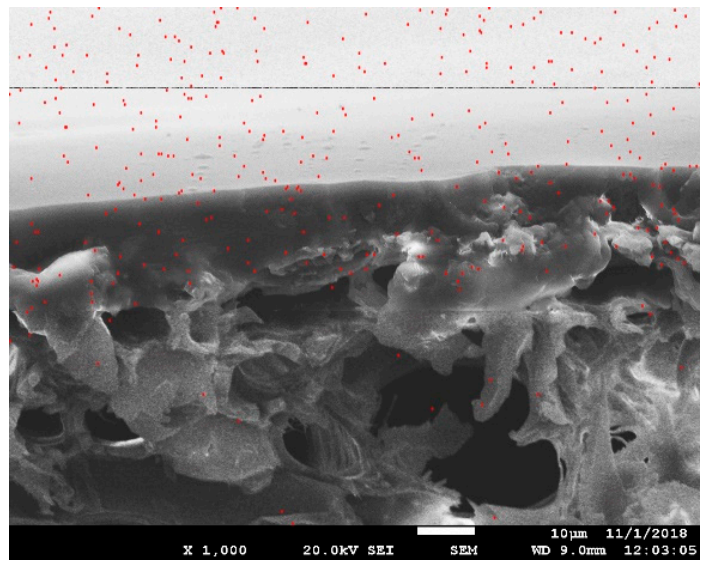

(a)

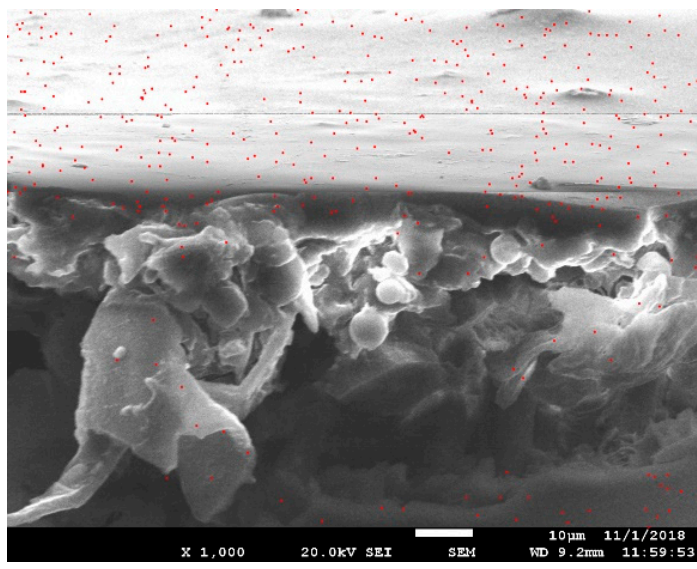

(b)

Figure 8. SEM-EDXA images for $\mathrm{N}$ distribution of oak after coating at different coating amount. (a) $12 \mathrm{~g} / \mathrm{m}^{2}$ PUA coated oak; (b) $60 \mathrm{~g} / \mathrm{m}^{2}$ PUA coated oak; the magnification was $\times 1000$.

\section{Conclusions}

The preparation and application of the fast water-based UV curing PUA wood coating was successful, where it can be completely cured within $22 \mathrm{~min}$. During curing, the hydroxyl groups in the oak reacted with the coating. It can be seen that as the coating amount increased, the number of hydroxyl groups decreased and the contact angle increased. At the same time, within a certain range, the adhesion, hardness and gloss value of oak surface increased to different extents. The coating coverage was improved and the surface gradually became smooth. The PUA can reach a depth of $35 \mu \mathrm{m}$ from the wood surface, and with the increase of coating amount, the filling degree of PUA coating in wood increased.

Author Contributions: Investigation, J.W. and H.W.; writing—original draft preparation, R.L.; conceptualization, L.L.; writing—review and editing, J.X.; resources, M.C.; data curation, H.Q.

Funding: This study was financially supported by the National Key Research and Development Program of China (No. 2016YFD0600704).

Conflicts of Interest: The authors declare no conflict of interest.

\section{References}

1. Xu, H.; Qiu, F.; Wang, Y.; Wu, W.; Yang, D.; Guo, Q. UV-curable waterborne polyurethane-acrylate: Preparation, characterization and properties. Prog. Org. Coat. 2012, 73, 47-53. [CrossRef]

2. Qi, L.; Guo, L.; Teng, Q.; Xiao, W.; Du, D.; Li, X. Synthesis of waterborne polyurethane containing alkoxysilane side groups and the properties of the hybrid coating films. Appl Surf. Sci. 2016, 377, 66-74.

3. Chang, C.W.; Lu, K.T. Epoxy acrylate UV/PU dual-cured wood cotings. J. Appl. Polym. Sci. 2012, 115, 2197-2202. [CrossRef]

4. Meijer, M.D. Review on the durability of exterior wood coatings with reduced VOC-content. Prog. Org. Coat. 2001, 43, 217-225. [CrossRef] 
5. Chang, W.Y.; Pan, Y.W.; Chuang, C.N.; Guo, J.J.; Chen, S.H.; Wang, C.K.; Hsieh, K.H. Fabrication and characterization of waterborne polyurethane (WPU) with aluminum trihydroxide (ATH) and mica as flame retardants. J. Polym. Res. 2015, 22, 243. [CrossRef]

6. Sun, Q.; Yu, H.; Liu, Y.; Li, J.; Lu, Y.; Hunt, J.F. Improvement of water resistance and dimensional stability of wood through titanium dioxide coating. Holzforschung 2010, 64, 757-761. [CrossRef]

7. Xu, H.; Qiu, F.; Wang, Y.; Yang, D.; Wu, W.; Chen, Z.; Zhu, J. Preparation, mechanical properties of waterborne polyurethane and crosslinked polyurethane-acrylate composite. J. Appl. Polym. Sci. 2012, 124, 958-968. [CrossRef]

8. Wang, Y.; Qiu, F.; Xu, B.; Xu, J.; Jiang, Y.; Yang, D.; Lia, P. Preparation, mechanical properties and surface morphologies of waterborne fluorinated polyurethane-acrylate. Prog. Org. Coat. 2013, 76, 876-883. [CrossRef]

9. Chou, P.L.; Chang, H.T.; Yeh, T.F.; Chang, S.T. Characterizing the conservation effect of clear coatings on photodegradation of wood. Bioresource Technol. 2008, 99, 1073-1079. [CrossRef]

10. Liu, F; Liu, G. Enhancement of UV-aging resistance of UV-curable polyurethane acrylate coatings via incorporation of hindered amine light stabilizers-functionalized $\mathrm{TiO}_{2}-\mathrm{SiO}_{2}$ nanoparticles. J. Polym. Res. 2018, 25, 59. [CrossRef]

11. Decker, C.; Masson, F.; Schewalm, R. How to speed up the UV curing of water-based acrylic coatings. JCT Res. 2004, 1, 127-136. [CrossRef]

12. Dai, J.; Ma, S.; Liu, X.; Han, L.; Wu, Y.; Dai, X.; Zhu, J. Synthesis of bio-based unsaturated polyester resins and their application in waterborne UV-curable coatings. Prog. Org. Coat. 2015, 78, 49-54. [CrossRef]

13. Montazeri, M.; Eckelman, M.J. Life cycle assessment of UV-Curable bio-based wood flooring coatings. J. Clean. Prod. 2018, 192, 932-939. [CrossRef]

14. Xu, J.; Jiang, Y.; Zhang, T.; Dai, Y.; Yang, D.; Qiu, F.; Yu, Z.; Yang, P. Synthesis of UV-curing waterborne polyurethane-acrylate coating and its photopolymerization kinetics using FT-IR and photo-DSC methods. Prog. Org. Coat. 2018, 122, 10-18. [CrossRef]

15. Decker, C.; Masson, F.; Schwalm, R. Weathering resistance of waterbased UV-cured polyurethane-acrylate coatings. Polym. Degrad. Stabil. 2004, 83, 309-320. [CrossRef]

16. Masson, F.; Decker, C.; Jaworek, T.; Schwalm, R. UV-radiation curing of waterbased urethane-acrylate coatings. Prog. Org. Coat. 2000, 39, 115-126. [CrossRef]

17. Sonmez, A.; Budakci, M.; Bayram, M. Effect of wood moisture content on adhesion of varnish coatings. Sci. Res. Essays. 2010, 12, 1432-1437.

18. Brown, G.L. Formation of films from polymer dispersions. J. Polym. Sci. A 1956, 102, 423-434. [CrossRef]

19. Hwang, H.D.; Park, C.H.; Moon, J.I.; Kim, H.J.; Masubuchi, T. UV-curing behavior and physical properties of waterborne UV-curable polycarbonate-based polyurethane dispersion. Prog. Org. Coat. 2011, 72, 663-675. [CrossRef]

20. Hahn, K.; Ley, G.; Schuller, H.; Oberthür, R. On particle coalescence in latex films. Colloid. Polym. Sci. 1986, 264, 1092-1096. [CrossRef]

21. Tong, T.; Lu, Z.; Zhou, G.; Jia, W.; Wang, M. Effect of air velocity in dehumidification drying environment on one-component waterborne wood top coating drying process. Dry. Technol. 2016, 34, 7372015-7373937. [CrossRef]

22. Yang, X.; Liu, J.; Wu, Y.; Liu, J.; Cheng, F.; Jiao, X.; Lai, G. Fabrication of UV-curable solvent-free epoxy modified silicone resin coating with high transparency and low volume shrinkage. Prog. Org. Coat. 2019, 129, 96-100. [CrossRef]

23. Yang, F.; Zhu, L.; Han, D.; Li, W.; Chen, Y.; Wang, X.; Ning, L. Preparation and hydrophobicity failure behavior of two kinds of fluorine-containing acrylic polyurethane coatings. Rsc Adv. 2015, 115, 95230-95239. [CrossRef]

24. Kong, X.; Qu, J.; Zhu, Y.; Cao, S.; Chen, H. Adhesion behaviors and affecting factors of polymer latexes. Paint. Coat. Ind. 2010, 40, 37-40.

25. Chu, H.H.; Chang, C.Y.; Shen, B.H. An electrophoretic coating using a nanosilica modified polyacrylate resin. J. Polym. Res. 2018, 25, 44. [CrossRef]

26. Asif, A.; Shi, W.; Shen, X.; Nie, K. Physical and thermal properties of UV curable waterborne polyurethane dispersions incorporating hyperbranched aliphatic polyester of varying generation number. Polymer 2005, 46, 11066-11078. [CrossRef] 
27. Asif, A.; Shi, W. UV curable waterborne polyurethane acrylate dispersions based on hyperbranched aliphatic polyester: Effect of molecular structure on physical and thermal properties. Polym. Adv. Technol. 2004, 15, 669-675. [CrossRef]

28. Asif, A.; Huang, C.Y.; Shi, W.F. Photopolymerization of waterborne polyurethane acrylate dispersions based on hyperbranched aliphatic polyester and properties of the cured films. Colloid. Polym. Sci. 2005, 283, 721-730. [CrossRef]

29. Asif, A.; Hu, L.; Shi, W. Synthesis, rheological, and thermal properties of waterborne hyperbranched polyurethane acrylate dispersions for UV curable coatings. Colloid. Polym. Sci. 2009, 287, 1041-1049. [CrossRef]

30. Phelps, J.E.; Workman, E.C., Jr. Vessel area studies in white oak (Quercus alba L.). Wood Fiber Sci. 1994, 26, 315-322.

31. Ozyhar, T.; Mohl, L.; Hering, S.; Hass, P.; Zeindler, L.; Ackermann, R.; Niemz, P. Orthotropic hygric and mechanical material properties of oak wood. Wood Mater. Sci. Eng. 2016, 11, 36-45. [CrossRef]

32. Catalin, C.; Cosmin, S.; Aurel, L.; Daniel, C.; Claudiu, R.I.; Alin, P.M.; Tibor, B.; Manuela, S.E.; Alexandru, P. Surface properties of thermally treated composite wood panels. Appl. Surf. Sci. 2018, 438, 114-126.

33. Xu, J.; Liu, R.; Wu, H.; Long, L.; Lin, P. A comparison of the performance of two kinds of waterborne coatings on bamboo and bamboo scrimber. Coatings 2019, 9, 161. [CrossRef]

34. Kuang, X.; Kuang, R.; Zheng, X.; Wang, Z. Mechanical properties and size stability of wheat straw and recycled LDPE composites coupled by waterborne coupling agents. Carbohyd. Polym. 2010, 80, 927-933. [CrossRef]

35. Landry, V.; Blanchet, P. Surface preparation of wood for application of waterborne coatings. For. Prod. J. 2012, 62, 39-45. [CrossRef]

(C) 2019 by the authors. Licensee MDPI, Basel, Switzerland. This article is an open access article distributed under the terms and conditions of the Creative Commons Attribution (CC BY) license (http://creativecommons.org/licenses/by/4.0/). 